\title{
Motion Control and Analysis of Delta-type a Parallel Robot
}

\author{
Tayfun $\mathrm{ABUT}^{1} \mathscr{\&}$, Servet SOYGÜDER ${ }^{2}$ \\ ${ }^{1}$ Department of Mechanical Engineering, Mus Alparslan University, 49100, Mus, Turkey \\ ${ }^{2}$ Department of Industrial Engineering, Ankara Yıldırım Beyazıt University, 06100, Ankara, Turkey \\ $\bowtie$ : tayfunabut@gmail.com, (DiD) 0000-0003-4646-3345, (D)2 0000-0002-8191-6891
}

Received (Geliş): 05.10.2021Ｒevision (Düzeltme):20. 11.2021Ａccepted (Kabul): 29.11.2021

\begin{abstract}
Parallel robots have natural advantages for many applications thanks to their high rigidity, high accuracy, low inertia of the moving parts and lightness, etc. The goal of this study has performed motion control, the kinematic and workspace analyses of a Delta-type parallel robot with 3 degrees of freedom (3-DOF). Delta-type parallel actual parameter values were used in the motion control and analyses. Forward and inverse kinematics analysis, as well as workspace analysis of the robot, were carried out. In addition, the motion control of the robot is actualized in Cartesian space. In order for the delta-type parallel robot to have zero oscillation and to have a robust structure against external disturbances, the Sliding Mode Control (SMC) method was preferred. As a result, the motion control, kinematics, and workspace analyses of the delta-type parallel robot were realized and examined.
\end{abstract}

Keywords: Delta type Parallel Robot, Kinematic and Workspace Analysis, Motion Control, SMC

\section{Delta Tipi Bir Paralel Robotun Hareket Kontrolü ve Analizi}

\section{ÖZ}

Paralel robotlar, yüksek rijitlikleri, yüksek doğrulukları, hareketli parçaların düşük ataletleri ve hafiflikleri vb. sayesinde birçok uygulama için doğal avantajlara sahiptir. Bu çalışmanın amacı, 3 serbestlik dereceli (3-DOF) Delta tipi bir paralel robotun hareket kontrolü, kinematik ve çalışma alanı analizlerini gerçekleştirmektir. Hareket kontrolü ve analizlerde delta tipi paralel robotun gerçek parametre değerleri kullanılmıştır. Robotun çalışma alanı analizinin yanı sıra ileri ve ters kinematik analizleri yapılmıştır. Ayrıca robotun hareket kontrolü kartezyen uzayda gerçekleştirilmiş̧tir. Delta tipi paralel robotun sıfır salınım yapması ve dışarıdan gelen bozuculara karşı sağlam bir yapıya sahip olması için Kayan Kipli Kontrol (KKK) yöntemi tercih edilmiştir. Sonuç olarak delta tipi paralel robotun hareket kontrolü, kinematik ve çalışma alanı analizleri gerçekleştirilmiş ve incelenmiş̧ir.

Anahtar Kelimeler: Delta tipi Paralel Robot, Hareket Kontrolü, Kinematik ve Çalışma Alanı Analizi, KKK

\section{INTRODUCTION}

In industrial works, robots are needed in flexible production systems, consisting of constantly changing dynamic processes. While most of the robots have open kinematic chain structure (also known as serial manipulator or anthropomorphic structures), parallel robots incorporate closed kinematic chain structures. Parallel manipulators are closed-type mechanisms, containing at least two independent kinematic loops and consisting of two platforms. The movable platform is dependent on a set of parts called the fixed platform feet at the base. As generally each leg is controlled by a separate actuator, system's degree of freedom is equal to the number of legs. As the juncture structure is nonserial, errors are not additive. They provide an advantage in terms of high-speed positioning due to having a more rigid construction. Parallel robots are closed-type parallel mechanisms created through attaching serially connected junction pieces to two platforms, one stationary and one movable, having 2 or more legs in a single axis of symmetry. Parallel delta robots are widely preferred in food, health, electricity and pharmaceutical industry due to their high-speed capacity and low footprint. Reasons for preference of parallel delta robots are their productivity, flexibility, quality, high performance period, ease of compatibility, low maintenance cost, etc. Delta robot with three degrees of freedom was developed by Clavel during 1990s. The robot moves in the three-dimensional space [1]. Clavel himself completed the kinematic and dynamic analysis of the manipulator [2]. Gosselin analyzed the workplace, namely the three-dimensional cartesian field within reaching distance from a point on the upper platform when orientated, of a parallel robot with 6 degrees of freedom [3]. Romdhane is the first researcher to address the problem of determining the workspace [4]. Workspace of these robots, having 3 degrees of freedom (DOF), is limited within an area in the three-dimensional cartesian field. The problem of determining the workspace was handled by authors, suggesting an algorithm allowing for determining certain parameters of parallel manipulators, using a genetic algorithm, in order to ensure a workspace as much approximate to the anticipated as possible [5-6]. Kosinska et al. presented a method for determining the parameters of a Delta-4 manipulator, applied to the workspace in a series of dots [7]. In another study, a new design method is presented that takes into account the desired working area and oscillation range of the ball joints of the delta robot. The rotation range of a 
spherical joint has been taken into account in the design approach and has proven to be effective and simple with an example [8]. Zheng carried out research on intelligent vibration suppression control of high-speed lightweight Delta robot [9]. New suggestions regarding kinematics and workspace of Delta-type parallel robots have been brought forward by Murray and yielded successful results [10-11]. Laribi et al. carried out a study involving the workspace and design analysis of a Delta-type parallel robot [12]. Maya et al. carried out a study on the workspace and bearing capacity of a new configurable delta parallel robot [13]. Riaño et al. proposed and implemented approaches based on a genetic algorithm for the optimal design of a delta parallel robot with vertical linear actuators [14]. In the study carried out by Lopez et al., forward and inverse kinematic analysis as well as the Jacobean matrix of a Delta-type parallel robot have been attained [15]. In order to improve the working performance of Delta robot, many researchers have conducted vibration suppression research [16-17]. The 4-DOF delta parallel robot has been designed to be used as a pick-and-place robot and has been examined by the mechanical interaction of this robot within its practical workspace. The authors proposed a new geometric algorithm to reduce mechanical collisions [18].

Préault et al. were presented new kinematics for the four degrees of freedom (DoF) robot based on the delta architecture. This new device is intended to be used as a tactile device for teleoperation applications. The robot improved based on the global parallel robot architecture was compared with the current robot in terms of kinematic behavior[19]. In another study in the literature, the delta type parallel robot was controlled with these methods in order to benefit from the adaptive and robust control advantages of adaptive control. Two adaptive methods were tried and compared on the delta type parallel robot [20].

Mitsantisuk et al. carried out a haptic system threedimensional work space analysis, involving a Delta robot-based master and slave robot, and furthermore, achieved sensor-free force control [21]. Shen et al. are carried out a study on the kinematic sensitivity, parameter definition, and calibration of the nonsymmetric parallel Delta robot [22]. Development, design and control studies of parallel robots have been researched by several researches up to date [23-26]. Boudjedir et al. were applied iterative learning controlDelta robot with non-repetitive trajectories for quadratic MIMO nonlinear systems [27].

$\mathrm{Wu}$ et al. worked on the disturbance observer-based trajectory tracking control of a delta-type parallel robot [28]. Ohno and Takeda researched the design of target trajectories for the detection of joint gaps in a parallel robot based on motor torque measurement [29]. The goal of this study has performed motion control, the kinematical and workspace analyses of a Delta type parallel robot with 3 degrees of freedom (3-DOF). Delta-type parallel actual parameter values were used in the motion control and analyses. Forward and inverse kinematics analysis, as well as workspace analysis of the robot, were carried out. In addition, the motion control of the robot is actualized in Cartesian space. In order for the delta-type parallel robot to have zero oscillation and to have a robust structure against external disturbances, the Sliding Mode Control (SMC) method was preferred. As a result, the motion control, kinematics, and workspace analyses of the delta-type parallel robot were realized and examined.

\section{MATERIAL and METHOD}

\section{System Overview and Analyses}

Parallel robots are closed-type parallel mechanisms created through attaching serially connected junction pieces to two platforms, one stationary and one movable, having 2 or more legs in a single axis of symmetry. In this section, kinematic and workspace analyzes of the system were done. Physical parameter values of the Delta type Parallel robot are provided on Table 1.

Table 1. The Physical Parameters of a Delta type Parallel robot

\begin{tabular}{ccc}
\hline Parameters & Values & Symbols \\
\hline $\mathrm{La}$ & 450 & $\mathrm{~mm}$ \\
$\mathrm{Lb}$ & 250 & $\mathrm{~mm}$ \\
$\mathrm{R}$ & 225 & $\mathrm{~mm}$ \\
$\mathrm{r}$ & 100 & $\mathrm{~mm}$ \\
\hline
\end{tabular}

\section{Kinematic Analyses}

\section{Forward and Inverse Kinematic}

Kinematic analysis is carried out in order that the position of the movable platform or the angles ensuring a certain position of the movable platform are determined based on the angles of the driven elements. Since driven elements in a delta robot are connected to the platform with swivel joints, the parameter determining the positions of such elements is the angle with the stationary element. The analysis in which position of the movable platform is calculated based on the angles of the driven elements is called "Forward Kinematic"; while the other is called "Inverse Kinematic". The Delta-type parallel robot is shown in Figure 1. In general, parallel robot is a closed-loop manipulator, which is rather inconvenient for kinematic calculation. The movable platform remains connected to the base platform, and the direction around the vertical axis on the base plate is zero at all times. As shown on Figure 2, it is stationary, movable platforms are circular with radius of $\mathrm{R}$, and $\mathrm{r}$. Junction points of stationary platform to stationary poles are S1, S2 and S3. X, y, and $\mathrm{Z}$ coordinates of these points are provided in Equation 1. Motors used in the movable and stationary platform have been placed with the angle of 1200. Geometrical parameters of the Delta-type parallel robot are shown on Figure 3. 


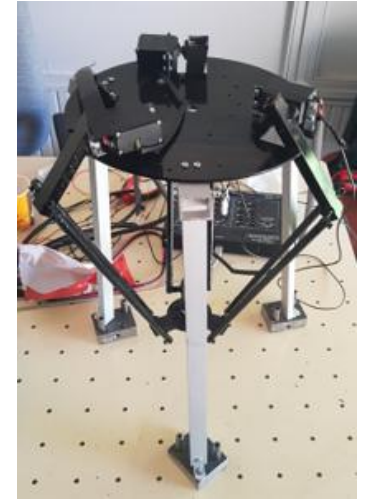

Figure 1. The Delta-type parallel robot

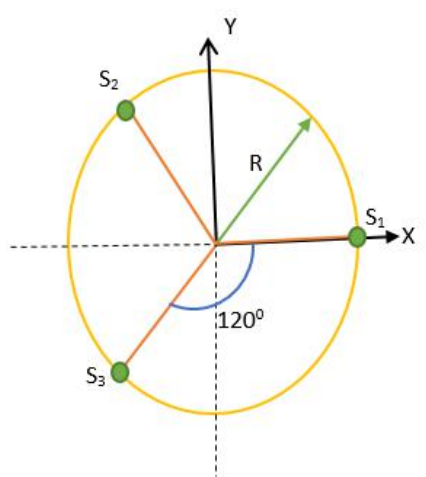

a)

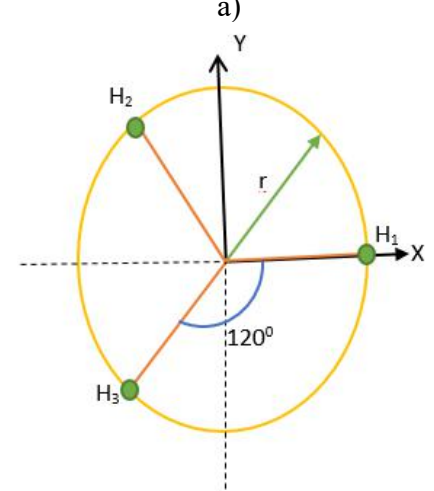

b)

Figure 2. Stationary and movable platform of the Delta-type parallel robot

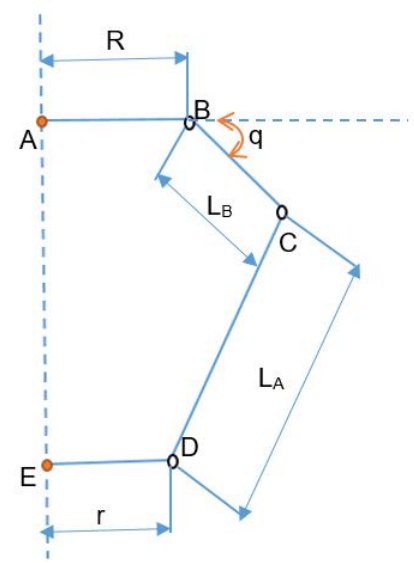

Figure 3. Geometrical parameters of the Delta-type parallel robot

$$
\left[\begin{array}{l}
S_{1} \\
S_{2} \\
S_{3}
\end{array}\right]=\left[\begin{array}{ccc}
R & -\frac{R}{2} & -\frac{R}{2} \\
0 & \frac{R \sqrt{3}}{2} & -\frac{R \sqrt{3}}{2} \\
0 & 0 & 0
\end{array}\right]
$$

Junction points of the movable platform to parallelograms are $\mathrm{H} 1, \mathrm{H} 2$ and $\mathrm{H} 3$ points. $\mathrm{X}, \mathrm{y}$, and $\mathrm{z}$ coordinates of these points are provided in Equation 2.

$\left[\begin{array}{l}H_{1} \\ H_{2} \\ H_{3}\end{array}\right]=\left[\begin{array}{ccc}r & -\frac{r}{2} & -\frac{r}{2} \\ 0 & \frac{r \sqrt{3}}{2} & -\frac{r \sqrt{3}}{2} \\ 0 & 0 & 0\end{array}\right]$

Forward kinematic equations, calculating the $\mathrm{XYZ}$ cartesian space of the robot's junction lead position in junction variable values through the use of such angles, were calculated as follows.

$$
\begin{aligned}
& x_{i}=\left(R+L_{A} \cos \theta_{i}\right) \cos \alpha_{i} \\
& y_{i}=\left(R+L_{A} \cos \theta_{i}\right) \sin \alpha_{i} \\
& z_{i}=L_{A} \sin \theta_{i} \\
& \left(x-x_{i}\right)^{2}+\left(y-y_{i}\right)^{2}+\left(z-z_{i}\right)^{2}=L_{B}{ }^{2}
\end{aligned}
$$

Geometrical parameters of the delta robot are $L_{A}, L_{B}, r, R$ and $\theta_{i}$ as defined on Figure 3 , and the variables are the junction angles defining the $i=$ $1,2,3 \ldots$ configuration. According to the aforementioned equations, there are three unknowns $(x, y, z)$. Therefore, three equations have been attained by replacing such unknowns with ' $i$ ' values.

$$
\begin{aligned}
& \left(x-x_{1}\right)^{2}+\left(y-y_{1}\right)^{2}+\left(z-z_{1}\right)^{2}=L_{B}{ }^{2} \\
& \left(x-x_{2}\right)^{2}+\left(y-y_{2}\right)^{2}+\left(z-z_{2}\right)^{2}=L_{B}{ }^{2}
\end{aligned}
$$

$\left(x-x_{3}\right)^{2}+\left(y-y_{3}\right)^{2}+\left(z-z_{3}\right)^{2}=L_{B}^{2}$

When the equations above are solved in turn and certain limitations were applied for ease of operation, the following equations were attained.

$$
\begin{aligned}
& x_{0}=\frac{a_{1} z_{0}+b_{1}}{d} \\
& y_{0}=\frac{a_{2} z_{0}+b_{2}}{d} \\
& z_{0}=\frac{-b \pm \sqrt{\Delta}}{2 a}
\end{aligned}
$$

In general, there are two possible solutions; which are the two possible configurations for the given junction angles from the movable platform to the base. Equation 13 was obtained upon use of an epitomic resultant vector value.

$\overrightarrow{S_{1} O}+\overrightarrow{O P}+\overrightarrow{P H_{1}}=\overrightarrow{S_{1} H_{1}}=L$ 
Inverse kinematic problem is caused by determining the $q_{i}(\mathrm{i}=1,2,3)$ angle values in cases of characteristic point or the end effector (TCP-Tool Center Point) positions based on general coordinates: $x_{p}, y_{p}, z_{p}$

$a_{i}+b_{i} \cos \theta_{i}+c_{i} \sin \theta_{i}=0$

$a_{i}=\left((R-r) \cos a_{i}-x\right)^{2}+\left((R-r) \operatorname{sina}_{i}-\right.$

$y)^{2}+z^{2}-L_{2}^{2}+L_{1}^{2}$

$b_{i}=2\left((R-r) \cos a_{i}-x\right) L_{1} \cos a_{i}+2((R-$

$\left.r) \sin _{i}-x\right) L_{1} \sin _{i}$

$c_{i}=2 z L_{1}$

$\theta_{i}=2 \arctan \frac{-c_{i} \pm \sqrt{c_{i}^{2}}\left(a_{i}^{2}-b_{i}^{2}\right)}{\left(a_{i}-b_{i}\right)}$

The equations provided above are the general equations intended for inverse kinematic analysis of the system.

\section{Workspace Analyses}

One of the most significant subjects in designing processes of parallel robots is determining the workspace. This can be even more critical for parallel robots, as they will, at times, have a highly limited workspace. In recent years, various numerical methods have been developed for determining the workspace of parallel robots. The following figures show the threedimensional robot workspace. The views of a) Threedimensional workspace, b) $\mathrm{XY}$, c) $\mathrm{XZ}$, d) $\mathrm{YZ}$ dimensions are shown in Figure 4.

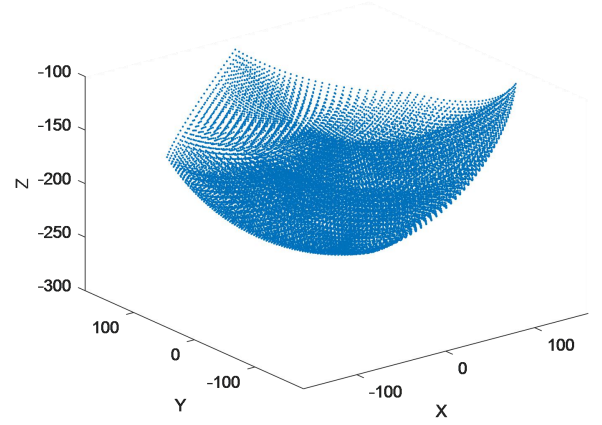

a)

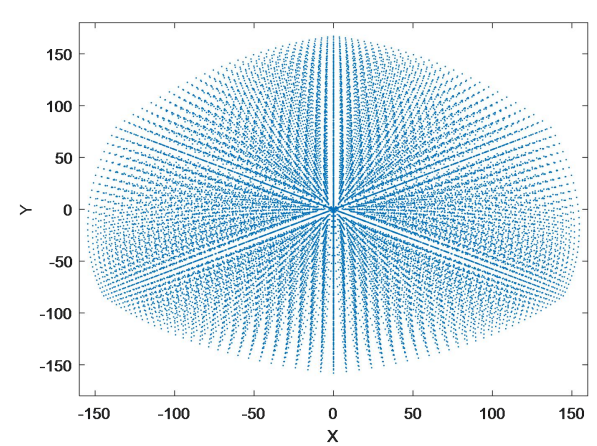

b)

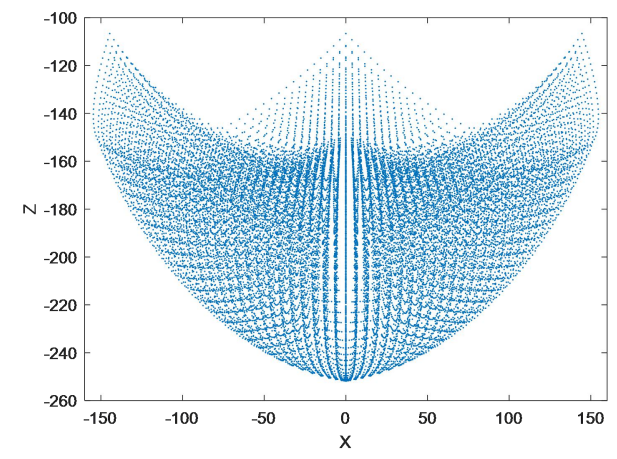

c)

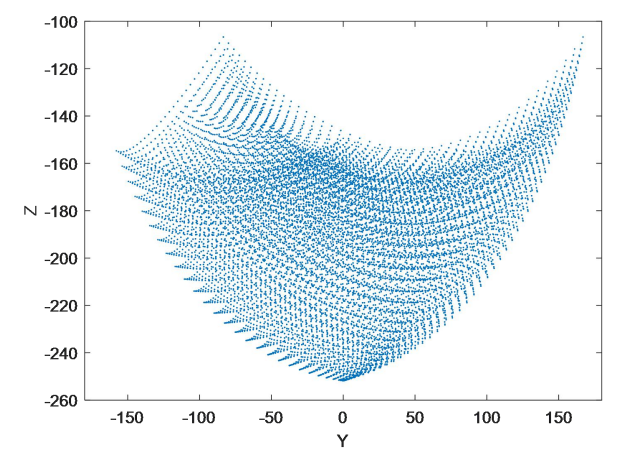

d)

Figure 4. Workspace of Delta type Parallel Robot

\section{Motion Controller Design}

The Sliding Mode Control (SMC) control method was used in motion control. This method was utilized in different works in the literature [30-36]. The goal of the control method is that the output value of the robot follows the reference value. The controller was tried to minimize the error. The block diagram of the SMC method is illustrated in Figure 5.

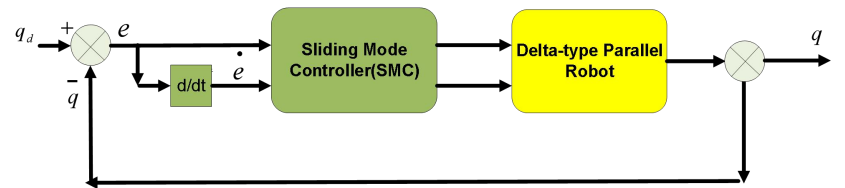

Figure 5. Control structure of the SMC method.

Error and time derivative of the error are given in Eq. (19) and Eq. (20), respectively.

$$
\begin{aligned}
& e(t)=q_{d}(t)-q(t) \\
& \dot{e}(t)=\dot{q}_{d}(t)-\dot{q}(t)
\end{aligned}
$$

In the above equation, $q_{d}$ denotes the desired joint trajectory and $q$ shows the real trajectory. The first and second-degree derivatives were used for the Eq. (19).

$S=\dot{e}-\lambda e$

$\dot{S}=\ddot{e}-\lambda \dot{e}$ 
where, $S$ represents the sliding surface and $\lambda$ is a positive defined symmetric matrix, $u$ control signal is given in Eq. 23. Saturation function is used to solve the chattering problem and $\phi$ shows the thickness of the boundary layer.

$$
\begin{aligned}
& u=-k \times \operatorname{sign}(s) \\
& \operatorname{sat}(s / \phi)=\left\{\begin{array}{cc}
\frac{s}{\phi} & \text { if }\left|\frac{s}{\phi}\right| \leq 1 \\
\operatorname{sign}(s / \phi) & \text { if }\left|\frac{s}{\phi}\right|>1
\end{array}\right.
\end{aligned}
$$

where, $k$ is the constant parameter and sign is a signal function and $s$ functions as a switch.

$$
u=k^{*} \operatorname{sat}(s)
$$

The selected function expression is given in equation 25 in order to perform stability analysis according to the Lyapunov function. The derivative of this expression must be less than zero. Therefore, $s$ should be negative (equation 26).

$$
\begin{aligned}
& V=\frac{1}{2} s^{2} \\
& \dot{V}=\dot{s} s<0
\end{aligned}
$$

\section{RESULT and DISCUSSION}

In this section, motion control simulation studies were carried out in Cartesian space and the results of the method are given graphically. Location-based control is achieved by converting a robot control problem into various motion control problems and each motor in the robot with position tracking control. Motion control with zero oscillations at the start and end positions of the road is often targeted to maintain zero swing values when picking and placing operations are performed. The sliding mode control method has been preferred for the delta type parallel robot to have zero oscillation and to have a robust structure against the externally impacting disruptors.

The robot was controlled by inverse kinematic equations. Control variables are the position values of $X$, $\mathrm{Y}$, and $\mathrm{Z}$. Simulation run time was taken as 8 seconds. Figure 6 shows the position-time responses of $X, Y$, and $\mathrm{Z}$ in the simulation environment in accordance with the desired reference input. Figure 7 illustrates the positiontime error responses of $\mathrm{X}, \mathrm{Y}$, and $\mathrm{Z}$. The results seem to be consistent as seen in Figure 6. Considering Figure 7, it is seen that the control method's positioning errors of the delta type parallel robot are effectively reduced to near zero as expected.

\section{CONCLUSION}

A study on kinematic and workspace analyses of a Delta type parallel robot with three degrees of freedom was made and motion control of the robot was performed. The robot's forward and inverse kinematic analyses and the robot's workspace analysis were performed. In addition, the robot's motion control was done using the Sliding Mode Control (SMC) method in Cartesian space. The crackling problem is solved by using the saturation function in the SMC control method. Therefore, the method has become simple and applicable. Given the motion control simulation results, it shows that the method provides good positioning accuracy. As a result, motion control, kinematic and work area analyzes of the delta type parallel robot has been made and examined.

\section{ACKNOWLEDGMENTS}

This study was supported within the scope of the TÜBITAK 2211/C Domestic Priority Areas Doctoral Scholarship Program.

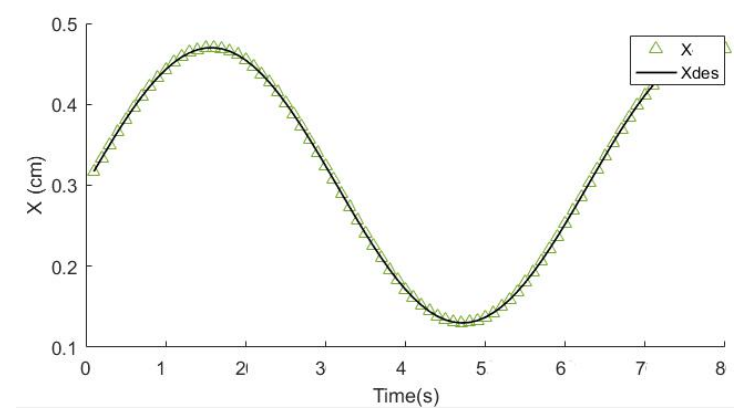

a)

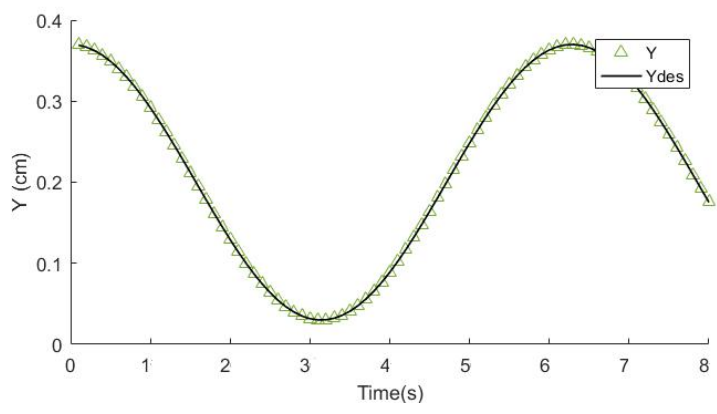

b)

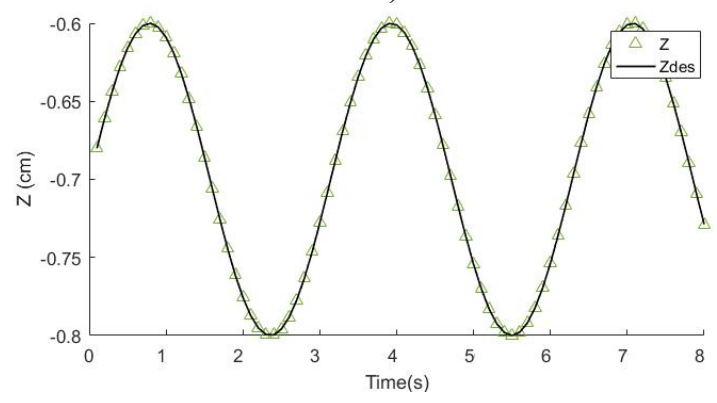

c)

Figure 6. Positions of (a) X, (b) Y, (c) and Z obtained by the reference values 


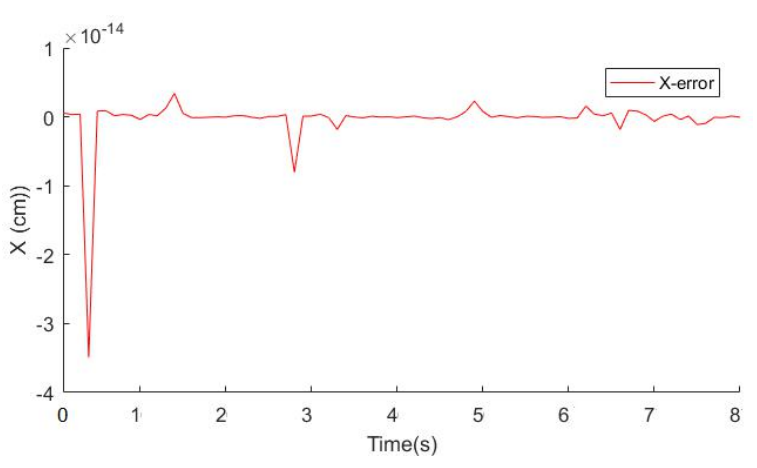

a)

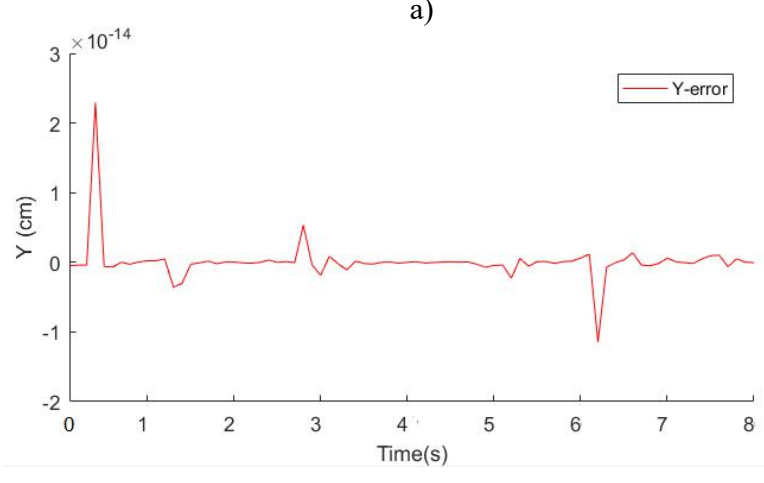

b)

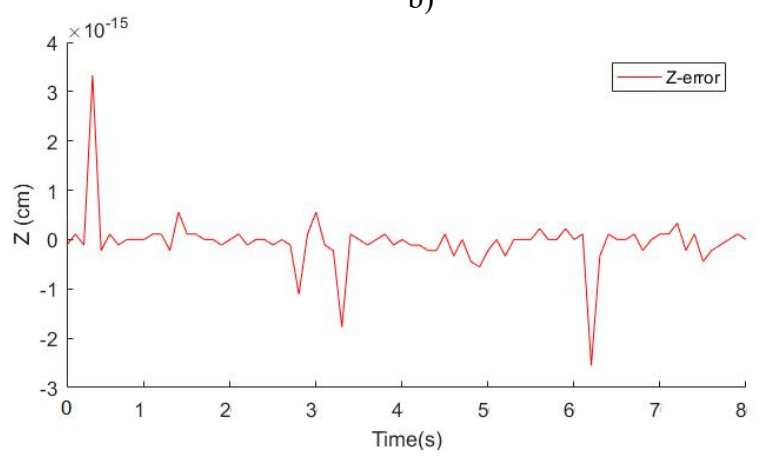

c)

Figure 7. Position error values $\quad$ (a) X, (b) Y, (c) Z

\section{REFERENCES}

[1] Clavel R. A fast robot with parallel geometry. In: Proc. Int. Symposium on Industrial Robots. 91-100. 1988.

[2] Clavel R. Conception d'un robot parallel rapide à quatre degrés de liberté (Doctoral dissertation, Ph. D. Thesis 925, Swiss Federal Institute of Technology (EPFL), Lausanne, Switzerland). 1991.

[3] Gosselin C. Determination of the workspace of 6-DOF parallel manipulators, ASME J. Mech. Des. 112 331-336, 1990.

[4] Romdhane L. Orientation workspace of fully parallel mechanisms, Eur. J. Mech. 13 541-553, 1994.

[5] Boudreau R., Gosselin C.M. The synthesis of planar parallel manipulators with a genetic algorithm, ASME J. Mech. Des. 121 533-537, 1999.

[6] Boudreau R., Gosselin C.M. La synthe'se d'une plate forme de Gough-Stewart pour un espace de travail atteignable prescrit, Mech. Mach. Theory 36 327-342, 2001.

[7] Kosinska A., Galicki M., Kedzior K. Design and optimization of parameters of Delta-4 parallel manipulator for a given workspace, J. Robot. Syst. 20:9 539-548, 2003.

[8] Liu X.J., Wang J., Oh K.K., Kim J. A New Approach to the Design of a DELTA Robot with a Desired Workspace. Journal of Intelligent and Robotic Systems, 39:2 209-225, 2004.

[9] Zheng K. Research on intelligent vibration suppression control of high-speed lightweight Delta robot. Journal of Vibration and Control, 10775463211024888, 2021.

[10] Zsombor-Murray P.J. Descriptive geometric, kinematic analysis of Clavel's Delta Robot; Centre of Intelligent Machines, McGill University, 2004.

[11] Zsombor-Murray P.J. An improved approach to the kinematics of Clavel's DELTA robot. Intelligent Machines, McGill University. 2009.

[12] Laribi M. A., Romdhane L., Zeghloul S. Analysis and dimensional synthesis of the DELTA robot for a prescribed workspace. Mechanism and machine theory, 42:7 859-870, 2007.

[13] Maya M., Castillo E., Lomelí A., González-Galván E., Cárdenas A. Workspace and payload-capacity of a new reconfigurable delta parallel robot. International Journal of Advanced Robotic Systems, 10:1 56, 2013.

[14] Riaño C., Peña C.E.S.A.R., Pardo A.L.D.O. Approach in the optimal development of parallel robot for educational applications. In Proceedings of the WSEAS international conference on Recent Advances in Intelligent Control, Modelling and Simulation (ICMS). 1452014.

[15] López M., Castillo E., García G., Bashir A. Delta robot: inverse, direct, and intermediate Jacobians. Proceedings of the Institution of Mechanical Engineers, Part C: Journal of Mechanical Engineering Science, 220:1 103109, 2006.

[16] Wu M., Mei J., Zhao Y., Niu, W. Vibration reduction of delta robot based on trajectory planning. Mechanism and Machine Theory, 153 104004, 2020.

[17] Zheng K., Zhang Q. Comprehensive analysis of the position error and vibration characteristics of Delta robot. Advanced Robotics, 30:20 1322-1340, 2016.

[18] Anvari Z., Ataei P., Masouleh M. T. Collision-free workspace and kinetostatic performances of a 4-DOF delta parallel robot. Journal of the Brazilian Society of Mechanical Sciences and Engineering, 41:2 99, 2019.

[19] Préault C., Saafi H., Laribi M.A., Zeghlou S. Optimal design and evaluation of a dexterous 4 DoFs haptic device based on delta architecture. Robotica, 37:7 1267$1288,2019$.

[20] Lu C., Miao X., Wang S., Zhang C. Research on Adaptive Robust Control Algorithm for Delta Parallel Robots. In Transactions on Intelligent Welding Manufacturing (pp. 59-68). Springer, Singapore. 2019.

[21] Mitsantisuk C., Stapornchaisit S., Niramitvasu N., Ohishi K., Force sensorless control with 3d workspace analysis for haptic devices based on Delta robot, Conference of the IEEE Industrial Electronics Society, IECON, p. 001747-001752, 2015.

[22] Shen H., Meng Q., Li J., Deng J., Wu G. Kinematic sensitivity, parameter identification and calibration of a non-fully symmetric parallel Delta robot. Mechanism and Machine Theory, 161 104311, 2021

[23] Lu X., Zhao Y., Liu M. Self-learning interval type-2 fuzzy neural network controllers for trajectory control of a Delta parallel robot. Neurocomputing, 283 107-119, 2018.

[24] Brinker J., Schmitz M., Takeda Y., Corves B. Dynamic Modeling of Functionally Extended Delta-Like Parallel Robots with Virtual Tree Structures. In ROMANSY 22Robot Design, Dynamics and Control (p. 171-179). Springer, Cham, 2019.

[25] Laryushkin P.A., Erastova K.G., Filippov G.S., Kheylo S.V. Calculation of Delta-Type Mechanisms with Linear Actuators and Different Numbers of Degrees of Freedom. 
[26] Journal of Machinery Manufacture and Reliability, 48:3 204-210, 2019.

[27] Brinker J., Corves B., Takeda Y. On the motion/force transmissibility and constrainability of delta parallel robots. In Computational kinematics. Springer, Cham, p. 340-348, 2018.

[28] Boudjedir, C.E., Bouri, M. Boukhetala, D. Model-free Iterative learning control with nonrepetitive trajectories for second-order MIMO nonlinear systems-application to a Delta robot. IEEE Transactions on Industrial Electronics, 68:8 7433-7443, 2020.

[29] Wu M., Mei J, Ni J, Hu, W. Trajectory tracking control of delta parallel robot based on disturbance observer. Proceedings of the Institution of Mechanical Engineers, Part I: Journal of Systems and Control Engineering, 235:7 1193-1203, 2021.

[30] Utkin V.I. Sliding mode control design principles and applications to electric drives, IEEE transactions on industrial electronics, 40:1 23-36, 1993.

[31] Abut T. Position Controller Design and Implementation of Ball and Beam System with SMC and PD Control Methods, Energy Engineering and Control Systems 6(2):120-126,2020.

[32] Utkin V. I., Chang H.C. Sliding mode control in electromechanical systems, Mathematical Problems in Engineering, 8:4-5 451-473, 2002.

[33] Abut T., Soyguder S. Sliding Mode Control of the Haptic-Teleoperation System Based on a Real and Virtual Robot. In 2019 International Artificial Intelligence and Data Processing Symposium (IDAP), IEEE, 1-7, 2019.

[34] Hüseyinoğlu M., Abut T. Dynamic model and control of 2-dof robotic arm. European Journal of Technique (EJT), 8:2141-150, 2018.

[35] Kim N.I., Lee C.W., Chang P.H. Sliding mode control with perturbation estimation: application to motion control of parallel manipulator. Control Eng Pract 6 1321-1330, 1998.

[36] Abut T., Soyguder S. Haptik-Teleoperasyon Sistemleri için PID ve SMC Kontrol Yöntemlerinin Tasarımı ve Bilgisayar Simülasyonu. Journal of New Results in Engineering and Natural Sciences, 12 12-21, 2020.

[37] Chen K.Y., Robust optimal adaptive sliding mode control with the disturbance observer for a manipulator robot system. Int J Control, Autom Syst 16:4 1701-1715, 2018. 